\title{
Explaining political participation: A comparison of real and falsified survey data
}

\author{
Uta Landrock \\ Department of Sociology, University of Kaiserslautern, 67663 Kaiserslautern, Germany \\ Tel.: +49 631205 4604; Fax: +49631205 4610; E-mail: landrock@sowi.uni-kl.de
}

\begin{abstract}
This paper examines differences between real survey data and data falsified by interviewers. Previous studies show that there are only small differences between real and falsified data which implies that falsifying interviewers are able to (re-)produce realistic frequency distributions. The question this paper aims to answer is whether they are also able to produce multivariate results in accordance with the assumptions of established social science approaches. As an example for a realistic theory-driven data analysis, real and falsified data are compared in terms of the identified determinants of political participation. I use an experimental data set with data partly collected in real interviews and partly by interviewers being instructed to falsify; that is, to fill in the questionnaire based on little information about the respondent. The questionnaire measures twelve political activities, based on which I calculate an index for political participation. There are differences in the models between the real and the falsified data: The explained variances are higher in the regression models of the falsified data. There are some variables significant in both data sets and some that are significant only in the real or in the falsified data. These differences can be explained by our theoretical assumptions.
\end{abstract}

Keywords: Interviewer falsifications, falsified survey data, data quality

\section{Falsification in surveys}

Face-to-face interviews are an important mode of data collection. The interviewers play a central role, since they can probe into unclear answers from the respondents, for example [1]. There is however, the risk that interviewers may falsify parts of, or the entire, interview (cp. [2]). Following the definition of the AAPOR, interviewer falsification "means the intentional departure from the designed interviewer guidelines or instructions, unreported by the interviewer, which could result in the contamination of data" ([3]: 1). The research question this paper aims to answer is how fabricated data affects the results of theory-driven multivariate analyses, using the example of explaining political participation.

But why do interviewers falsify survey data? Falsifying interviewers want to optimize their cost-benefit balance. That means, they want to fulfill their tasks and objectives (conducting the interviews, achieving a high response rate, maximizing the payment etc.) with a minimal effort and resources (time and travel expenditures, convincing the survey respondents to participate, etc.). Thus the behavior of the interviewers follows the logic of rational choice approaches: To save effort and time, interviewers can decide to falsify [4,5].

In addition, the falsifying processes themselves underlie a cost-benefit calculation. On the one hand, falsifying interviewers want to reduce their cognitive effort when choosing answer categories. On the other hand, they want to prevent detection as falsifiers, which implies that they must fabricate answers which could plausibly be the true answers of the respondents [6,7]. To reduce their cognitive effort, falsifiers apply satisficing strategies: Satisficing means that the falsifiers do not search for the optimal answer on a certain question; they search for an acceptable answer, one which appears to be plausible on first thought $[6,8]$. Respondents in a real interview situation are assumed to use satisficing strategies since they also want to reduce cognitive effort when choosing answer categories [8].

To quickly evaluate the plausibility of answers, falsifiers apply general stereotypes and implicit every- 
day knowledge $[9,10]$. By stereotyping, falsifiers are able to reproduce the means and marginal distributions in high accordance with reality, as described later in this section [9-11]. The same stereotypes and implicit models of response behavior can also lead to a higher consistency of the falsified interviews [10], particularly since the existing variations which accompany different socio-demographic characteristics are overestimated by the interviewers [9]. Aside from the higher consistency and the differences in the covariance structure there are further indications for falsification, for example in the meta- and para-data and also regarding different formal indicators like response sets (e.g. acquiescent responding or primacy and recency effects) as Menold and Kemper [7] have shown.

Reliable information on the exact proportion of falsifications in surveys does not exist; different authors indicate that it does not exceed five percent (e.g., [12-14]). However, there are examples of surveys where the percentage of falsifications is much higher under certain circumstances $[15,16]$. In previous studies only small differences in the proportions and means were identified when real and falsified data were compared [9,10]. Menold and Kemper [7] also report large similarities between real and falsified data, especially in attitudinal and behavioral questions. However, findings on the impact of falsified data on the covariance structure of data prove that even small proportions of falsifications can contaminate data substantially [9-11].

To explore the impact of falsified survey data on the results of data analysis, Schnell [10] and Reuband [9] both produced artificially falsified data in the lab, which they compare with real survey data. The real survey data in both studies were subsamples from factually existing data sets. Basic demographic information from some of the real survey respondents were provided to the study participants, who were recruited as falsifiers. The falsifiers were asked to use this demographic information to invent responses to the survey questions. Schnell [10] used subjective political competence as a dependent variable in a regression analysis. The explaining variables were net income, selfreported social class, and self-placement on the topbottom scale. In his regression analysis, the explained variance was higher in the falsified than in the real data. While in the falsified data all three independent variables had significant effects, in the real data only two of the three independent variables were significant [10]. Reuband [9] analyzed the effects of age and gender on the attitude towards abortion. The results of his regres- sion analysis also show that the explained variances were higher and the effects stronger in the falsified than in the real data [9].

Furthermore, Schraepler and Wagner [11] applied a regression analysis to explore the impact of falsified survey data on the results of a multivariate analysis. They used data from the German Socio Economic Panel, which included real and falsified data. The data were collected in a real survey field setting; the falsified data were afterwards identified as "real" interviewer falsifications. The dependent variable of the regression analysis was the log of gross income. The explaining variables were age and gender, the duration of training, and the working hours per week of the respondent. Schraepler and Wagner [11] report that the inclusion of falsified data in their analysis reduces the explained variance and biases the effect sizes in different directions. Compared to the data set, which consists exclusively of real data, the effects of age and gender were overestimated and the effects of duration of training and working hours per week were underestimated [11].

The previous studies in this field of research show that falsifications in surveys affect the results of data analyses, particularly the covariance structure, often resulting in an overestimation of correlations and of explained variance. Nevertheless, the correlations that were investigated were intuitive, based rather on ad hoc than on theoretically deducted hypotheses; for this reason, it is possible that they meet the assumptions of the stereotypes which falsifiers use in their satisficing strategies. As a consequence, one can assume that the overestimation of correlations in falsified data holds only or particularly for cases in which a falsifier would expect a relationship, for example because of stereotypes or implicit knowledge. In contrast to these above mentioned studies Landrock and Menold [17] compared real and falsified data by applying a certain social science theory, the theory of planned behavior, and conducted theory-driven regression analyses for explaining healthy eating behavior. They came to the result that stereotypical and non-theory-driven relationships were more strongly pronounced in the falsified data while theory-driven relationships were more strongly pronounced in the real data. Apart from their work, until now, little is known about how the differences between fabricated and real data appear when theory-driven assumptions are tested. This paper intends to reduce this research gap by answering the research question whether falsifiers are able to produce multivariate results on political participation in 
accordance with the assumptions of established social science approaches and thus how fabricated data affects the results of theory-driven multivariate analyses. Thereby it aims to give further evidence that falsifiers are not fully able to reproduce the complex relationships of real data.

\section{Analyses and results}

As we know from previous research, falsifiers are often able to invent plausible answers and produce realistic frequency distributions. They are also able to produce correlations that exist in real data, which they often even overestimate, as long as these correspond to customary stereotypes and are intuitively guessable. The research question raised here therefore is how correlations are affected by falsified data that are theoretically deducted and well-grounded in existing scientific literature. I analyze differences between real and falsified data using theory-driven multivariate analyses to identify the determinants for political participation. I decided to apply the example of explaining political participation because this is a widely researched question in social sciences with high social relevance.

\subsection{Hypotheses}

The question of whether falsifiers are able to produce data in accordance with the assumptions of established social science approaches is anything but evident. One can reasonably assume that falsifiers are typically not familiar with these social science approaches and do not apply them - also because this would imply investing more cognitive effort and would contradict the falsifiers' satisficing strategies. A core assumption of the following analyses therefore is that the more causal effects are rooted in social science theoretical approaches rather than in everyday knowledge, the less they can be produced by falsifiers and the less they are found in falsified data. This assumption leads to the following four hypotheses:

- H1: For the theoretically predicted determinants there are more significant effects in the real than in the falsified data.

Falsifiers reproduce and eventually overestimate effects that they assume to be true, typically because they are obvious or intuitive, such as the influence of the self-placement on the left-rightdimension. In contrast, the effects predicted by elaborate social science theories, such as the in- fluence of political efficacy, are less likely to be intuitive for falsifiers. And unless they have an academic background, the falsifying interviewers probably do not know the underlying theoretical bases of a study. Therefore, they should generally not be able to reproduce relationships that are explained by these bases and that are empirically proven in reality by the existing research literature. ${ }^{1}$ Instead, they apply implicit stereotypes and everyday knowledge about the attitudes and behavior of the respondents. If this assumption is correct, this should be reflected in the results of the theory-driven causal analysis. Consequently, H1 states that there are more significant effects for the theoretically predicted determinants in the real than in the falsified data.

- H2: For real socio-demographic information known to falsifying interviewers, there are more significant effects in the falsified than in the real data. As described above, previous research has found that falsifiers overestimate the existing sociodemographic differences between the respondents [9]. Furthermore, they have only little information about the respondents and their living conditions. Therefore, the falsifiers strongly rely on socio-demographic information that they happen to know or that is provided to them and give a particularly high relevance to such information. ${ }^{2}$ Consequently, $\mathrm{H} 2$ states that within socio-demographic information known to falsifiers, there are more significant variables in the falsified than in the real data.

- H3: For further correlates found in research, there are more significant effects in the falsified than in the real data.

Beyond the ground of strict theoretical deduction, there are further correlates found in research which enter the bases of scientific knowledge and are typically also used in subsequent research for formulating hypotheses and designing multivariate regression models. In the case of research on political participation, there are such independent variables which have been proven in previous empirical studies to be relevant under certain circum-

\footnotetext{
${ }^{1}$ It seems to be plausible that more experienced falsifiers are able to guess these less obvious relationships without knowing the social science theory behind.

${ }^{2}$ Nevertheless, it seems to be plausible that the level of overestimation of socio-demographic information depends on the knowledge of the subject and the experience of the falsifier.
} 
stances (cp. Section 2.3). They mostly have an influence in specific contexts, depending on the concrete form of the analyzed political participation. These influences are more obvious and principally guessable by laymen as they were by experts. Based on their laymen's theories and everyday knowledge, the falsifiers invent answers and construct stereotypical relationships with the likewise fabricated attitudes and behaviors. The real respondents instead answer more inconsistently, perhaps due to their more complex life conditions and the occurrence of satisficing. Therefore, the falsifiers overestimate the relationships and construct more significant effects in the falsified data than observable in the real data. Consequently, H3 states that there are more significant effects of the further correlates found in the falsified than in the real data.

- H4: The falsifiers construct more consistent cases than real life; therefore, the explained variance is higher in the falsified than in the real data.

An invented pattern of answers to a questionnaire follows less complex principles and shows fewer inconsistencies than the empirical realities created by real life. Therefore, all in all, the falsifiers invent more consistent models of respondents' behavior than the real respondents show. This leads to more consistent regression models in the falsified than in the real data. ${ }^{3}$ As a result, the explained variances, measured as adjusted Rsquared, should be higher in the falsified than in the real data.

\subsection{Database and method}

Data sets with confirmed real and confirmed falsified interviews rarely exist; therefore usually experimental data are used for the empirical analysis of the effects of falsifications (cp. [18]). The database in this paper consists of three datasets, obtained in the summer of 2011, and is described in detail by Kemper and Menold [19] as well as by Menold and Kemper [7]:

For the first dataset, 78 interviewers conducted 710 real face-to-face interviews. The interviewers were students at the University of Giessen. The respondents were students at the University of Giessen as well and were recruited on the campus. All interviews

\footnotetext{
${ }^{3}$ The higher consistencies of the falsifiers may vary on different factors, for example the length of the questionnaire.
}

were audio-recorded and checked afterwards to assure that they were actually conducted and not falsified. The questionnaire contains 62 questions on attitudes and behavior and socio-demographic information, mainly adopted from the German General Social Survey (ALLBUS ${ }^{4}$ ) with political, economic and social topics. Payment was provided either per interview ( 8 euro) or per hour (12 euro) to the interviewers (e.g., [19]).

For the second dataset, the same interviewers fabricated survey data in the lab so that a data set of 710 falsified interviews, corresponding to each of the $N=$ 710 real interviews, was obtained. For this task, either 9 euros per hour or 3 euros per falsified interview was paid. The falsifying interviewers received basic sociodemographic information about the real survey participants, for whom they were supposed to invent data and who had been interviewed by a colleague (not by themselves) in the first part of the study. The information the interviewers were given was of such a kind that a falsifying interviewer could easily have collected him- or herself via a short interview with the respondent: sex, age, studied subject, number of semesters enrolled, marital status, place of residence, living situation (with whom the respondent lives in a household), and country of origin (e.g., [19]).

The interviewers were instructed to imagine a person with these characteristics and to fill in the questionnaire, thus falsifying the data as if they were collected in a real survey setting. The exact instruction was:

Please read the description of the person, whose interview you are supposed to falsify, carefully. Please fill in the attached questionnaire as if you had conducted a personal interview with the respondent in reality. Please place the description of the respondent next to the questionnaire while falsifying, so that you are always aware of the characteristics of this person.

The person, whose interview is to falsify...

- is female,

- is 20 years old,

- studies teaching,

- is enrolled in her second semester at a university.

- She is unmarried, in a stable relationship,

- lives in Huettenberg, a rural village in Hesse,

- with her parents or relatives.

- Country of birth: Germany.

\footnotetext{
${ }^{4}$ http://www.gesis.org/en/allbus/allbus-home/.
} 
Additionally, in the third phase of the fieldwork, the interviewers filled in the survey questionnaire for themselves, as respondents, and also a questionnaire about their falsifying strategies. These data are stored in a third data set.

This experimental setup has strengths and weaknesses. On the one hand, it allows the collection of a lot of information about the interviewers and their falsifying processes. In comparison to a standard field setting, this is a relevant strength. A significant limitation of this experimental design is the fact that interviewers and respondents were students. As a result, some of the sociodemographic variables, like age or education, show only small variances (cp. [18]).

I use the two data sets with real and with falsified answers from the respondents for calculating multivariate causal analysis and comparing results to find out which differences occur with the use of not only real but also falsified data.

\subsection{Political participation}

Following the definition of the political action study of Barnes and Kaase et al. [20], political participation includes all activities of individual citizens, which are voluntary and intended to influence political decisions directly or indirectly ([21, p. 42]). Political participation has been differentiated in two forms. On the one hand, conventional political participation covers forms of participation which are related to political elections and party activities ([22, p. 84]), such as engagement in a party or participation in public discussions (cp. [23]). On the other hand, unconventional political participation means forms of participation which are independent of political elections and party activities ([23, p. 12]; [21, p. 41]), such as participation in demonstrations or house squatting, which means occupying an abandoned house without permission (cp. [23]). However, the contrast between the two forms has diminished during the last decades since most forms of unconventional political participation used to be considered as illegitimate by large parts of society and are considered as fully legitimate today. In current literature this differentiation is mostly neglected, since it is considered as "analytically elegant, but difficult to keep up empirically" ([24, p. 203]).

The question arises, which factors have an impact on the degree to which individuals engage in political participation. There are different models which aim to explain political participation (cp. [25]). In the political action study, Kaase and Marsh ([21, p. 43]) devel- oped a "heuristic device" ([21, p. 41]), which is helpful to explain political participation, but "is not meant to be a systematic specification of causal relationships" ([21, p. 41]). Based on this instrumental concept, Opp developed a rational choice model of explaining political participation (cp. [25,26]) which is acknowledged and frequently used today, for example, it is the theoretical foundation for the German General Social Survey (ALLBUS, cp. [23]). According to Opp, the following dimensions are considered as determinants for political participation (see also [23,25]): dissatisfaction with the political, economic or social situation, the perceived influence on political decisions, the existence of norms of political participation, and social incentives for political engagement.

The theoretical assumption is that the more people are dissatisfied with their political, economic or social situation, the stronger is their political participation. Recent research has provided empirical evidence for this assumption. For example, Steinbrecher [27] proves the positive effect of political dissatisfaction on political participation. The perceived influence on political decisions is captured by the concept of political efficacy, which covers two dimensions: the internal and the external. Internal political efficacy means an individual's perception of his or her own ability to influence political decisions. External political efficacy means the actor's perception that the political system will react ([21, p. 48-49]). The political efficacy transforms a disposition to participate in factual participation and can therefore be considered a precondition for political participation (cp. [21]). The higher the political efficacy is the stronger is the political participation. Opp and Finkel [26], Lüdemann [25], as well as Steinbrecher [27] report evidence for the positive impact of political efficacy. A third influencing dimension covers the perception of participation norms; the stronger the perceived norms to participate are the stronger is the political participation (cp. [26]). The dimension of social incentives refers to the social relations and memberships an actor has in organizations in which participation is likely to be supported, for example in political parties, citizens' action groups or other associations (see also [24]). The theoretical expectation is that higher social integration in such supporting organizations and social networks should be positively correlated with stronger political participation. Opp and Finkel [26] for example provide evidence for this assumption.

Aside from these influencing dimensions, many studies consider additional influencing factors. These 
factors mostly have an influence in specific contexts, depending on the concrete form of participation that is analyzed (for example conventional or unconventional forms or legal or illegal forms). Marsh and Kaase [22] identify in the political action study the effects of socio-demographic variables like age, gender, and education. Opp and Finkel [26], Westle [28] and Steinbrecher [27] confirm the significance of these variables: Opp and Finkel [26] report a positive relationship between age and protest as unconventional political participation, whereas Steinbrecher [27] identify a negative relationship. Westle [28] shows that men participate politically more often than women do. Opp and Finkel [26] as well as Steinbrecher [27] report a positive relationship between education and political participation. There are further correlates, which have influences on political participation: Kaase and Marsh [21] describe the self-placement on the leftright scale as a complementing indicator, with people classifying themselves as rather politically left being more active. The same result is reported by Lüdemann [25]. Furthermore, there is evidence for the positive influence of the self-reported social class on political participation [22]. For TV consumption, Lüdemann [25] and Schulz [29] report a negative correlation with political participation. As one can see there is a broad variety of influencing correlates.

\subsection{Operationalization and regression model}

To operationalize political participation, which serves as the dependent variable, the questionnaire contains material adopted from the German General Social Survey (ALLBUS) 2008, which covers 12 different conventional and unconventional activities (cp. [30]). Just as in the original ALLBUS 2008 item-scale, not only the factual behavior in the past is obtained for each activity, but also the intention to participate politically in the future (idem).

The exact wording of the two questions regarding the intention to participate and the factual behavior in the past is:

If you wanted to have political influence or to make your point of view felt on an issue which was important to you: Which of the possibilities listed on these cards would you use? Which of them would you consider? Please name the corresponding letters.

[letters A to M, see below]

Which of these things have you actually already done, what have you already taken part in? Please name the corresponding letters.
A. Express your opinion to friends and acquaintances and at work

B. Vote at elections

C. Take part in public discussions at meetings

D. Participate in a citizens' action group

E. Voluntary work for a political party

F. Take part in an unauthorized demonstration

G. Take part in an authorized demonstration

H. Not vote at elections out of protest

J. Out of protest, vote for a party other than your party of choice

K. Sign a petition

L. Boycott or buy goods for political, ethical or environmental reasons

M. Take part in an online protest campaign

Marsh and Kaase [22], and following them also Steinbrecher [27], Westle [28], Schulz [29] and other researchers, use the readiness to participate politically as an indicator for political participation. In the work presented in this paper, it is operationalized accordingly. One reason for including readiness in the operationalization is the assumption that factual political participation in the past supports and determines the current readiness for political participation (cp. [28]). Another reason refers to the chronological order of cause and effect: the interview measures factual participation in the past and other information, such as attitudes or socio-demographic characteristics, at the time of the interview. This makes it difficult to consider the current attitudes or other interview information as influencing factors for political participation, which occurred prior to the measurement of these potential causes (cp. [27]). Therefore it seems convincing to use readiness or intention to participate as indicators for political participation and as dependent variables.

To identify the latent structure of the political activities and to generate a suitable indicator for political participation, I conducted an exploratory factor analysis using the twelve forms of past political participation as well as readiness for political participation (cp. [24,25,27], and others). As a result, I identified four factors of past political activities and also four factors of readiness for political participation. The most reliable factor, with a Cronbach's Alpha of 0.6, covers the readiness for political participation, consisting of the readiness for participation in a citizens' action group (item D), the readiness for participation in public discussions (item $\mathrm{C}$ ), and the readiness for engagement in a party (item E). I calculated an additive index as an indicator for political participation and dependent variable for the further analysis. Steinbrecher [27] 
identified in his analysis of the ALLBUS data almost the same factor, ${ }^{5}$ which he calls party activities.

The explaining variables are organized in three blocks. The first block covers the theoretically expected determining factors for political participation as described by Opp and Finkel ([26], see above), the second block consists of socio-demographic and control variables provided to the falsifiers, and the third block refers to the further situationally relevant correlates found in research.

As described before, following Opp's explanation for political participation, there are four determining factors: political efficacy, dissatisfaction, norms of participation, and social incentives (cp. [26]).

In the data set, political efficacy is differentiated in two forms, measured with two items each. The internal political efficacy is measured as in agreement with the following items from ALLBUS 1998 (cp. [23]):

I would have the confidence to take on an active role in a group concerned with political issues.

Politics is so complicated that somebody like me can't understand what's going on at all. [Reversed item]

The external political efficacy covers the agreement with the following items from ALLBUS 1998 (idem):

Politicians don't care much about what people like me think. [Reversed item]

In general, politicians try to represent the people's interests.

As independent variables for the analysis, the means of both items were each calculated [23,30].

Following the operationalization of the ALLBUS 1998, dissatisfaction is obtained as political and economic dissatisfaction. To measure political dissatisfaction, the mean of the agreement with three statements is used [23]:

Only when differences in income and social status are large enough is there any incentive for personal achievement.

Differences in social position between people are acceptable because they basically reflect what one has made of the chances one had.

I consider the social differences in this country to be just on the whole.

\footnotetext{
${ }^{5}$ Steinbrecher's factor additionally covers the item "supporting a candidate", which is not used in ALLBUS 2008 and neither in my questionnaire.
}

The economic situation is measured just as in ALLBUS 1998, in accordance with two items [23]. Here I did not calculate an index because of the low Value of Cronbach's Alpha (.26):

How would you generally rate the current economic situation in Germany?

And your own current financial situation?

Information on the norms of participation and social incentives are not available in the used data set.

The second block of independent variables covers socio-demographic information which is provided to the falsifiers. These variables are known to have effects on political participation [22]. Furthermore, this information is used by the falsifier to invent the survey data. I included age and gender, but not education, which was also provided, because all respondents are students.

In the third block of independent variables, I included indicators which were reported as situationally relevant for political participation; these variables are self-placement on the left-right scale [21], self-reported social class (idem), and TV consumption [25,29]. In ALLBUS 2008, the attractiveness of the respondent, as reported by the interviewer, is assumed to have a positive effect on political participation, because psychological research has shown that attractive people consider themselves to be more influential than others [30]. Thus, I also included this variable as situationally relevant.

These independent variables were included in a linear OLS regression analysis, which was calculated for real and for falsified data identically, to compare the results of the real and the falsified data.

\subsection{Results}

The following table (Table 1) shows the results of the regression analysis for the real and the falsified data.

Model 1 includes the theoretically expected determining factors for political participation, which are less obvious for falsifiers. In the real data, three of the five determining factors show significant effects. The correlations of internal political efficacy and political dissatisfaction are positive, as expected. In contrast to the theoretical assumptions, there is a negative influence of dissatisfaction with an individual's own economic situation on political participation. In addition, Westle [28] and Opp and Finkel [26] cannot confirm any (positive) effects of dissatisfaction. Opp 
Table 1

OLS regression analysis - determinants of political participation in real and in falsified data

\begin{tabular}{|c|c|c|c|c|c|c|}
\hline \multirow[b]{3}{*}{ Included variables } & \multicolumn{3}{|c|}{ Real data } & \multicolumn{3}{|c|}{ Falsified data } \\
\hline & Model 1 & Model 2 & Model 3 & Model 1 & Model 2 & Model 3 \\
\hline & Beta (sign.) & Beta (sign.) & Beta (sign.) & Beta (sign.) & Beta (sign.) & \\
\hline \multicolumn{7}{|l|}{ Determining factors for participation: } \\
\hline Internal political efficacy & $0.38(0.000)$ & $0.41(0.000)$ & $0.40(0.000)$ & $0.47(0.000)$ & $0.49(0.000)$ & $0.46(0.000)$ \\
\hline External political efficacy & $0.02(0.636)$ & $0.01(0.797)$ & $0.00(0.926)$ & $-0.01(0.734)$ & $-0.02(0.612)$ & $-0.01(0.722)$ \\
\hline $\begin{array}{l}\text { Dissatisfaction with the general economic } \\
\text { situation in Germany }\end{array}$ & $0.00(0.949)$ & $-0.01(0.791)$ & $0.00(0.999)$ & $0.04(0.355)$ & $0.04(0.387)$ & $0.03(0.469)$ \\
\hline $\begin{array}{l}\text { Dissatisfaction with individual economic } \\
\text { situation }\end{array}$ & $-0.08(0.029)$ & $-0.08(0.033)$ & $-0.07(0.067)$ & $-0.01(0.900)$ & $0.00(0.979)$ & $-0.01(0.859)$ \\
\hline Political dissatisfaction & $0.13(0.000)$ & $0.12(0.001)$ & $0.11(0.006)$ & $0.06(0.097)$ & $0.06(0.128)$ & $0.01(0.727)$ \\
\hline \multicolumn{7}{|l|}{ Control variables provided to falsifiers: } \\
\hline Age & & $-0.02(0.515)$ & $-0.02(0.518)$ & & $0.01(0.860)$ & $0.01(0.797)$ \\
\hline Gender $=$ female (reference: male) & & $0.08(0.033)$ & $0.08(0.034)$ & & $0.09(0.023)$ & $0.08(0.048)$ \\
\hline \multicolumn{7}{|l|}{ Further correlates found in research: } \\
\hline $\begin{array}{l}\text { Self-placement on the left-right-dimension } \\
(1=\text { right, } 10=\text { left })\end{array}$ & & & $0.00(0.942)$ & & & $0.13(0.002)$ \\
\hline $\begin{array}{l}\text { Self-reported social class (reference: } \\
\text { upper middle class and higher) }\end{array}$ & & & $-0.04(0.271)$ & & & $-0.04(0.387)$ \\
\hline TV-consumption (min/day) & & & $-0.06(0.100)$ & & & $-0.03(0.370)$ \\
\hline $\begin{array}{l}\text { Attractiveness of respondent, reported by } \\
\text { the interviewer }\end{array}$ & & & $-0.03(0.414)$ & & & $0.01(0.801)$ \\
\hline Adj. $R^{2}$ (sign.) & $0.16(0.000)$ & $0.17(0.000)$ & $0.17(0.000)$ & $0.21(0.000)$ & $0.22(0.000)$ & $0.23(0.000)$ \\
\hline
\end{tabular}

and Finkel [26] argue in their analysis that the respondents assume that they cannot reduce their dissatisfaction by participating politically, which seems to apply in this study as well. Furthermore, in this study the respondents are students. It doesn't seem plausible to assume that students, who are dissatisfied with their own economic situation, would be willing to participate politically in the forms of participation that are analyzed here (cp. Section 2.4). It seems more convincing that these students would concentrate on the success of their studies to change their economic situation as soon as possible. Consequently, they would be less likely to willingly participate politically, as compared to students who are satisfied with their economic situation. This effect, however, is not in line with the theoretically-developed hypotheses. Aside from the three effects described, there are no significant effects in the first block: external political efficacy and dissatisfaction with the general economic situation in Germany do not influence political participation.

Falsified data from model 1 contained only one significant variable: internal political efficacy. The other four theoretically expected determining factors for political participation remain without significant effects. This finding is generally in line with the first hypothesis, stating that for the theoretically predicted determinants, which are less obvious for falsifiers, there are more significant effects in the real than in the falsified data. Still, the question arises as to how the falsifiers are able to reproduce the correlation between in- ternal political efficacy and political participation. This effect is even stronger in the falsified data than it is in the real data. One possible answer is that the two statements which measure internal political efficacy ${ }^{6}$ are relatively coarse and are therefore, for the falsifiers obviously related to political participation, without scientific knowledge. The adjusted $\mathrm{R}$ squared of 0.21 in the falsified data is higher than the value of 0.16 in the real data. Although only one independent variable is significant in the falsified data, the falsified model is more consistent than the model for the real data. The falsifiers only recognize the relevance of one theoretically predicted determinant, the internal political efficacy, but they overestimate its influence, similarly as it was predicted in hypotheses 2 and 3 for the determinants that are not grounded on theoretical approaches.

Model 2 additionally includes the control variables provided to falsifiers. These are the sociodemographic information of the real respondents regarding age and gender that are accurate also in the data set of falsified data, so that possible differences in the results can only occur due to the dependent variable. In the real data, age has no effect on political participation, presumably because of the low variance within the age range of this sample of students. Gender has a significant influ-

\footnotetext{
${ }^{6}$ The two statements are: "I would have the confidence to take on an active role in a group concerned with political issues" and "Politics are so complicated that somebody like me can't understand what's going on at all" (see also section operationalization).
} 
ence on political participation: In this sample, women participate politically more frequently than men.

Results in the falsified models are quite similar: The effect of gender is also provable and follows the same direction. Age is not significant in the falsified data either, presumably for the same reason as in the real data. These results do not support the assumption that falsifiers overestimate the sociodemographic information they happen to have, which contradicts the second hypothesis. One can conclude, however, that falsifiers use the information about gender to falsify the questionnaires. The question arises of how the falsifiers are able to guess the influence of gender, and also in the correct direction, with women being more engaged than men, which seems stereotypically contradictory. One explanation may be that the falsifiers have experience conducting real interviews prior to falsifying their data, which may have given them a good impression regarding gender differences in the sample. This is a weakness of the data set which might corrupt our findings. The adjusted $\mathrm{R}$ squared is still higher in model 2 in the falsified data, with two significant independent variables, than in the real data, with four significant independent variables. This difference is still due to the variables of the first block, particularly due to the impact of internal political efficacy.

The final model 3 includes additional correlates found in research, which are reported as situationally relevant for political participation and more obvious for falsifiers. In the real data, none of the further correlates show any significant effect; for the "party activities," as Steinbrecher [27] calls the forms of political participation used here for operationalization, these variables do not make a difference. Furthermore, in model 3, dissatisfaction with the individual's own economic situation loses its significant influence. Internal political efficacy and political dissatisfaction remain the only two significant determining factors for political participation.

In the falsified data there is a significant effect of self-placement on the left-right-dimension: The falsifiers assume that self-placement on the left-rightdimension has a significant influence on political participation, with those defining themselves as rather left being more engaged. This is in line with the third hypothesis, stating that for further correlates, there are more significant effects in the falsified than in the real data. The adjusted $\mathrm{R}$ squared value in the falsified data slightly increases to 0.23 in model 3 and is still higher in comparison to the real data. Thus, the falsifiers' model of political participation is more consistent than in reality.
To summarize the results of the regression analysis I will review the hypotheses:

- H1 states: For the theoretically predicted determinants, there are more significant effects in the real than in the falsified data.

This hypothesis is confirmed. In all three models, there are more significant determining factors in the real than in the falsified data. The final model 3 shows two significant effects in the real data, namely effects of internal political efficacy and of political dissatisfaction. In model 3 , regarding the falsified data, only internal political efficacy has a significant effect: The falsifiers do not guess the impact of political dissatisfaction. So, there is some support for H1. On the other hand, the support for $\mathrm{H} 1$ could be stronger: There is still one significant effect in the falsified data, even if it is an influence that seems intuitively guessable; and, there are only a few significant effects of the determining factors for political participation in the real data. As previously mentioned, other researchers cannot confirm any (positive) impact of dissatisfaction (cp. [26,28]). The same applies to external political efficacy [27]. In conclusion, the results presented here for the real data are in accordance with research on political participation.

- H2 states: For real socio-demographic information known to falsifying interviewers, there are more significant effects in the falsified than in the real data.

This hypothesis is not confirmed. In each of the three models in both subsamples, gender has a significant effect on political participation but age does not. This contradicts the hypothetical assumptions of more significant effects in the falsified than in the real data. One reason probably is that age only has a small variance in this student sample. The second reason may be that the falsifiers have gained an idea about the actual gender differences in the sample before they falsified via experience conducting real interviews. So, it is very possible that the lack of support for $\mathrm{H} 2$ is due to weaknesses in the data set and its methodological design.

- H3 states: For further correlates found in research, there are more significant effects in the falsified than in the real data.

This hypothesis is confirmed. One can see that there is one variable, self-placement on the leftright-dimension, with a significant effect in the falsified data, but none in the real data. This is 
in line with H3. However, again, there could be stronger support. It can be assumed that falsifiers do not have many applicable stereotypes regarding readiness for political participation. This may have to do with the dependent variable: Readiness is a pretty vague construct. Also, it could be that more unconventional forms of political participation, for example participating in demonstrations, would activate more stereotypes in the expected way, in contrast to the engagement in a party or participating in a citizens' action group or participating in public discussions, which are considered in this analysis.

- H4 states: The falsifiers construct more consistent cases than in real life; therefore, the explained variance should be higher in the falsified than in the real data.

This hypothesis is confirmed. The results regarding $\mathrm{H} 4$ meet the expectations of a higher explained variance in the falsified than in the real data. The falsifiers seem to invent more consistent cases in all three models.

The corrected R-squared value of 0.17 is not very high in the real data. This corresponds to the findings of Steinbrecher [27], who analyses different forms of readiness for political participation and reports corrected R-squared values between 0.10 and 0.21 in his analyses of ALLBUS data. Steinbrecher [27] argues that these results indicate that political participation depends highly on the context.

It can be summarized that three of the four hypotheses find support, even if the support is not very strong. Only $\mathrm{H} 2$ is left without confirmation.

\section{Conclusion and discussion}

The present work started out from the observation that falsifying interviewers are, on the one hand, able to invent plausible answers to survey questions. On the other hand, previous studies show that interviewer falsifications in surveys affect the results of data analyses, mostly leading to an overestimation, partly also to an underestimation of influences. This paper was inspired by the assumption that an overestimation of influences would occur for variables to which an influence seemed intuitively plausible, based on implicit laymen's theories and stereotypes, whereas an underestimation would occur for variables whose influence seemed less obvious. The latter can be expected for ef- fects predicted by elaborate social science theory approaches. The paper therefore intended to answer the question of whether or not falsifiers are able to produce data in accordance with the assumptions of established social science approaches. Explaining political participation is a suitable example for investigating this question, because there is a well-established theoretical approach with proven survey questions and measurements (for example in the 1998 and 2008 ALLBUS questionnaires). Furthermore, political participation is a highly relevant topic in the social sciences.

As described in the results above, there are differences in the models between the real and the falsified data: The explained variances are higher in the regression models of the falsified data. Furthermore, correlations are present in the falsified data that cannot be proven in the real data, which supports the assumption that falsifiers use stereotypes or implicit knowledge for inventing realistic answers to interview questions. Finally, the falsifiers were not able to reproduce both effects of the theoretically predicted determinants for political participation, in particular the effect of political dissatisfaction on the readiness for political participation. As one can see, the falsifiers are not fully able to produce data in accordance with the assumptions of established social science approaches. These findings underline that good results of multivariate analysis, in terms of strong significant effects and high shares of explained variance, do not necessarily imply good data quality; they might as well be a hint for falsifications. Therefore it is crucially important for empirical research to put much effort in avoiding falsifications. And it is important to identify falsifications, for example using the formal indicators investigated by Menold and Kemper [7]. Comparing subsamples with suspicious and with unsuspicious cases based on theory-driven multivariate analysis could be an additional strategy in examining a data set for falsifications.

Despite the fact that our hypotheses do find support, there are fewer differences between real and falsified data than one could expect. This probably has four reasons: First, the falsifying interviewers were familiar with the typical responses of the interviewees because they had conducted real interviews before they falsified. That is also the case in real fieldwork, where real interviewers who falsify may have conducted true interviews beforehand. Second, the respondents, as well as the interviewers, were students, leading to the possible bias that the interviewers are acquainted with the thinking and the habits of the interviewed population. 
Third, there are different social science theories that are more or less "intuitive" for laymen and therefore easier or harder to reproduce for falsifiers. The theoretically predicted explaining variables for political participation are, partly, intuitive, in particular the effect of internal political efficacy. Fourth, there are dependent variables that are more or less suitable for applying stereotypes. Aside from the intuitive explaining variables mentioned above, there are only a few stereotypes related to the readiness for political activities. One may find better-suited dependent variables to activate stereotypes and to make the differences between real and falsified data visible, for example, explaining activities like participation in demonstrations.

Nevertheless, the main finding of this paper is that falsifiers overestimate the influence of stereotypical causes and they are less able to reproduce theoretically-induced relationships. Thus this paper validates the results of Landrocks and Menolds previous work [17] and gives another piece of evidence that complex relationships in the real data are difficult for falsifiers to reconstruct.

\section{Acknowledgements}

Our research team gratefully acknowledges financial support through the DFG in projects WI 2024/5-4 and ME 3538/4-1. I thank Natalja Menold for her support and consult on this paper.

\section{References}

[1] TW. Mangione, FJ. Fowler and TA. Louis, Question characteristics and interviewer effects, Journal of Official Statistics 8(3) (1992), 293-307.

[2] S. Bredl, N. Storfinger and N. Menold, A literature review of methods to detect fabricated survey data. in: Interviewers' Deviations in Surveys, P. Winker, N. Menold and R. Porst, eds, Frankfurt: Peter Lang 2013, pp. 3-24.

[3] AAPOR. Interviewer Falsification in Survey Research: Current Best Methods for Prevention, Detection and Repair of Its Effects. 2003 [cited 2015 May 15]. Available from: http:// www.aapor.org/pdfs/falsification.pdf.

[4] W. Sodeur, Entscheidungsspielräume von Interviewern bei der Wahrscheinlichkeitsauswahl, Methoden Daten Analysen 1(2) (2007), 107-130.

[5] P. Winker, Assuring the quality of survey data: Incentives, detection and documentation of deviant behavior, Statistical Journal of the IAOS 32(3) (2016), 295-303. doi: 10.3233/SJI161012.

[6] N. Menold, P. Winker, N. Storfinger and CJ. Kemper, A method for ex-post-identification of falsifications in survey data. in: Interviewers ' Deviations in Surveys, P. Winker, N. Menold and R. Porst, eds, Frankfurt: Peter Lang 2013, pp. 25-48.
[7] N. Menold and CJ. Kemper, How do real and falsified data differ? Psychology of survey response as a source of falsification indicators in face-to-face surveys, International Journal of Public Opinion Research 26(1) (2014), 41-65. doi: 10.1093/ijpor/edt017.

[8] JA. Krosnick and D. Alwin, An evaluation of a cognitive theory of response-order effects in survey measurement, Public Opinion Quarterly 51(2) (1987), 201-219.

[9] K-H. Reuband, Interviews, die keine sind. "Erfolge" und "Mißerfolge" beim Fälschen von Interviews, Kölner Zeitschrift für Soziologie und Sozialpsychologie 42(4) (1990), 706-733.

[10] R. Schnell, Der Einfluss gefälschter Interviews auf SurveyErgebnisse, Zeitschrift für Soziologie 20(1) (1991), 25-35.

[11] J-P. Schraepler and GG. Wagner, Identification, Characteristics and Impact of Faked Interviews in Surveys, An analysis by means of genuine fakes in the raw data of SOEP. IZA Discussion Paper No. 969, Forschungsinstitut zur Zukunft der Arbeit, 2003.

[12] A. Koch, Gefälschte Interviews: Ergebnisse der Interviewerkontrolle beim ALLBUS 1994, ZUMA-Nachrichten 36 (1995), 89-105

[13] EA. Krejsa, MC. Davis and JM. Hill, Evaluation of the Quality Assurance Falsification Interview used in the Census 2000 Dress Rehearsal, Proceedings of the American Statistical Association (Survey Research Methods Section) 1999, 635-640.

[14] J. Li, JM. Brick, B. Tran and P. Singer, Using Statistical Models for Sample Design of a Reinterview Program, Proceedings of the American Statistical Association (Survey Research Methods Section) 2009, 4681-4695.

[15] N. Kuriakose and M. Robbins, Don't get duped: Fraud through duplication in public opinion surveys, Statistical Journal of the IAOS 2016, 1-11.

[16] S. Koczela, C. Furlong, J. McCarthy and A. Mushtaq, Curbstoning and beyond: Confronting data fabrication in survey research, Statistical Journal of the IAOS 31 (2015), 413-422.

[17] U. Landrock and N. Menold, Validation of theoretical assumptions with real and falsified survey data, Statistical Journal of the IAOS 32(3) (2016), 305-312. doi: 10.3233/SJI161020.

[18] P. Winker, K-W. Kruse, N. Menold and U. Landrock, Interviewer effects in real and falsified interviews: Results from a large scale experiment, Statistical Journal of the IAOS 31(3) (2015), 423-434. doi: 10.3233/SJI-150908.

[19] CJ. Kemper and N. Menold, Nuisance or remedy? The utility of stylistic responding as an indicator of data fabrication in surveys, Methodology. 2014. Advanced online publication. doi: 10.1027/1614-2241/a000078.

[20] SH. Barnes, M. Kaase, KR. Allerbeck, BG. Farah, F. Heunks, R. Inglehart, MK. Jennings, D. Klingemann, A. Marsh and L. Rosenmayr, eds. Political Action. Mass Participation in Five Western Democracies, Beverly Hills (CA): Sage, 1979.

[21] M. Kaase, A. Marsh and A. Political, A Theoretical Perspective. in: Political Action. Mass Participation in Five Western Democracies, SH. Barnes and M. Kaase, eds, Beverly Hills (CA): Sage 1979, pp. 27-56.

[22] A. Marsh and M. Kaase, Measuring Political Action. in: Political Action. Mass Participation in Five Western Democracies 27-56, SH. Barnes and M. Kaase, eds, Beverly Hills (CA): Sage 1979, pp. 57-96.

[23] A. Koch, K. Kurz, H. Mahr-George and M. Wasmer, Konzeption und Durchführung der "Allgemeinen Bevölkerungsumfrage der Sozialwissenschaften" (ALLBUS) 1998. Mannheim: ZUMA-Arbeitsbericht 1999/02. 1999 [homepage on 
the Internet, cited 2014 Sep 30] Available from: http://nbnresolving. de/urn:nbn:de:0168-ssoar-200413.

[24] JW. van Deth, Soziale und politische Beteiligung: Alternativen, Ergänzungen oder Zwillinge? in: Politische Partizipation in der Bundesrepublik Deutschland. Empirische Befunde und theoretische Erklärungen, A. Koch, P. Schmidt and M. Wasmer, eds, Opladen: Leske und Budrich 2001, pp. 196219.

[25] C. Lüdemann, Politische Partizipation, Anreize und Ressourcen. Ein Test verschiedener Handlungsmodelle und Anschlusstheorien am ALLBUS 1998. in: Politische Partizipation in der Bundesrepublik Deutschland. Empirische Befunde und theoretische Erklärungen, A. Koch, P. Schmidt and M. Wasmer, eds, Opladen: Leske und Budrich 2001, pp. 196219.

[26] KD. Opp and SE. Finkel, Politischer Protest, Rationalität und Lebensstile. Eine empirische Überprüfung alternativer Erklärungsmodelle. in: Politische Partizipation in der Bundesrepublik Deutschland. Empirische Befunde und theoretische Erklärungen, A. Koch, P. Schmidt and M. Wasmer, eds, Opladen: Leske und Budrich 2001, pp. 73-108.
[27] M. Steinbrecher, Politische Partizipation in Deutschland, Baden-Baden: Nomos, 2004.

[28] B. Westle, Politische Partizipation und Geschlecht. in: Politische Partizipation in der Bundesrepublik Deutschland. Empirische Befunde und theoretische Erklärungen, A. Koch, P. Schmidt and M. Wasmer, eds, Opladen: Leske und Budrich 2001, pp. 132-168.

[29] W. Schulz, Politische Mobilisierung durch Mediennutzung? Beziehungen zwischen Kommunikationsverhalten, politischer Kompetenz und Partizipationsbereitschaft. in: Politische Partizipation in der Bundesrepublik Deutschland. Empirische Befunde und theoretische Erklärungen, A. Koch, P. Schmidt and M. Wasmer, eds, Opladen: Leske und Budrich 2001, pp. 170-194.

[30] M. Wasmer, E. Scholz and M. Blohm, Konzeption und Durchführung der "Allgemeinen Bevölkerungsumfrage der Sozialwissenschaften" (ALLBUS) 2008. GESIS-Technical Reports 2010; 2010/04. 